\title{
Os sentidos mudam e a cozinha também: análise da(s) formação(ões) discursiva(s) das propagandas da Todeschini
}

\author{
Heitor Pereira de Lima* \\ Kátia Regina de Sousa e Silva**
}

\begin{abstract}
Resumo
Este trabalho parte da compreensão de que a noção de formação discursiva corresponde a um domínio de saber, constituído de enunciados discursivos que representam um modo de relacionar-se com a ideologia vigente, regulando o que pode e deve ser dito (PÊCHEUX, 1988). Nesse sentido, evocase a noção de sujeito, categoria analítica que difere pontualmente o quadro teórico da Análise do Discurso de linha francesa pêcheuxtiana das demais teorias que também contemplam o discurso. Embora este ensaio assume seu interesse por formação discursiva, não pretendemos perder de vista a noção de tomada de posição, formações ideológicas e sujeito, como já anunciamos, uma vez que a reunião dessas noções é fundamental para que consigamos acesso aos efeitos de sentido mobilizados pelas formações discursivas (estas a serviço de ideologia) que autorizam o discurso. Para isso, utilizaremos como corpus três textos propagandísticos da empresa de cozinhas planejadas Todeschini e buscaremos aporte teórico em Michel Pêcheux (1988), por sua importância na teorização do conceito de formação discursiva pela qual foi possível, ao considerar as formações ideológicas, esgarçar o olhar sobre essa categoria analítica tão cara aos estudos discursivos; Michel Foucault (1969), pela sua preocupação em estabelecer as regularidades, os sistemas de dispersão; e Freda Indursky (2020) por compreender sua relevância às pesquisas que visam explorar formações discursivas, sobretudo àquelas que elegem corpus da realidade brasileira.
\end{abstract}

Palavras-chave: Formação discursiva. Tomada de posição. Formação ideológica. Sujeito.

\footnotetext{
* Mestrando do Programa de Pós-Graduação em Letras - Linguística e Língua Portuguesa/PUC Minas. Integrante do Grupo de Pesquisa NELLF da mesma instituição. Bolsista CNPq. https://orcid.org/0000-0002-3247-4847.

** Mestranda do Programa de Pós-Graduação em Letras - Linguística e Língua Portuguesa/PUC Minas. Bolsista CAPES. Professora da Rede Pública Municipal de Belo Horizonte/MG. https://orcid.org/0000-0003-2324-553X.
}

Cadernos CESPUC de Pesquisa. Série Ensaios. n.37, $2^{\circ}$ Sem./2020, p. 200-216. e-ISSN: 2358-3231 (OJS). Recebido em: 08/10/2020. Aceito em: 21/10/2020. 


\title{
The Directions Change and the Kitchen al so: Analysis of the Discursive Formation(s) of Todeschini Advertisements
}

\author{
Heitor Pereira de Lima \\ Kátia Regina de Sousa e Silva
}

\begin{abstract}
This work starts from the understanding that the notion of discursive formation corresponds to a domain of knowledge, constituted of discursive statements that represent a way of relating to the prevailing ideology, regulating what can and should be said (PÊCHEUX, 1988). In this sense, the notion of subject is evoked, an analytical category that punctually differs from the theoretical framework of Pêcheuxtian French Discourse Analysis from other theories that also contemplate discourse. Although this essay assumes its interest in discursive formation, we do not intend to lose sight of the notion of taking a position, ideological formations and subject, as we have already announced, since the gathering of these notions is fundamental for us to gain access to the effects of meaning mobilized by discursive formations (these at the service of ideology) that authorize discourse. For this purpose, we will use as corpus three advertising texts from the planned kitchen company Todeschini and seek theoretical support in Michel Pêcheux (1988), for their importance in theorizing the concept of discursive formation through which it was possible, when considering ideological formations, to stretch the gaze about this analytical category so dear to discursive studies; Michel Foucault (1969), for his concern in establishing regularities, dispersion systems; and Freda Indursky (2020) for understanding its relevance to research aimed at exploring discursive formations, especially those that elect corpus from the Brazilian reality.
\end{abstract}

Keywords: Discursive formation. Position taking. Ideological formation. Subject. 


\section{Colocando a mão na massa}

Essas plataformas movediças sem as quais não se poderia ter percorrido a estrada pela primeira vez... (PÊCHEUX, 1966).

Este ensaio surge a partir das discussões realizadas durante a disciplina Análise do Discurso, ofertada pelo Programa de Pós-graduação em Letras da Pontifícia Universidade Católica de Minas Gerais (PUC Minas), que abordou, dentre vários, um operador teórico-analítico importantíssimo ao analista do discurso: formações discursivas. Embora o bom desenho da disciplina tenha nos proporcionado, de modo estendido, reflexões sobre esse operador, tomando Michel Pêcheux, Michel Foucault e alguns pesquisadores brasileiros que estudam sobre o assunto, assumimos os postulados pêcheuxtianos como horizonte, neste trabalho, por entendermos que a discussão promovida pelo iniciador da Escola Francesa da Análise do Discurso, ao perceber que as formações ideológicas são preponderantes nas regiões de sentido, vai além de estabelecer as regularidades, os sistemas de dispersão.

A noção de formação discursiva (a partir de agora FD) é revisitada/ tomada frequentemente, seja pelas pesquisas científicas que buscam legitimar visões que garantam a paternidade do termo a quem faz jus, ou ainda, pelas situações ordinárias da vida cotidiana que buscam possibilidades de "desvendar" os efeitos de sentido, sem o compromisso acadêmico-científico.

$\mathrm{O}$ nosso trabalho caminha em direção oposta às mencionadas: compreender como a textualização de um discurso, materializada num texto verbal, numa fotografia, numa pintura etc., ou seja, por qualquer semiose, é autorizada por uma FD que legitima o dizer, bem como a forma como se diz, tendo aí um efeito de homogeneidade; por outro lado, como esse mesmo discurso, ao ser inscrito em outras FDs e, portanto, ideológicas, passa mobilizar sentidos diferentes por meio daquilo que Pêcheux chamou de tomada de posição, o que configura a manifestação da heterogeneidade. Segundo Pêcheux: 
[...] a tomada de posição resulta de um retorno do 'Sujeito' no sujeito, de modo que a não-coincidência subjetiva que caracteriza a dualidade sujeito/objeto, pela qual o sujeito se separa daquilo de que ele 'toma consciência' e a propósito do que ele toma posição, é fundamentalmente homogênea à coincidência-reconhecimento pela qual o sujeito se identifica consigo mesmo, com seus 'semelhantes' e com o 'Sujeito'. O 'desdobramento' do sujeito - como 'tomada de consciência' de seus 'objetos' - é uma reduplicação da identificação [...] (PÊCHEUX, 1988, p. 172).

Diante do exposto, reiteramos que este estudo pretende debruçar-se sobre noção de FD, ancorado no arcabouço teórico da Análise do Discurso de linha francesa que tem Michel Pêcheux como iniciador.

Há ainda outro ponto a ser considerado neste ensaio à guisa de consideração inicial: a necessidade de que sigamos na urgência de compreender a relevância das FDs para os estudos que discorrem sobre o discurso. Freda Indursky, grande pesquisadora brasileira que estuda esse assunto, já nos questionava em seu texto "Formação Discursiva: ela ainda merece que lutemos por ela?” (2007b) sobre a necessidade de apostar num conceito tão importante aos estudos discursivos, sobretudo, àqueles que não abandonam a noção de formações ideológicas.

Uma vez que percebemos o corpus selecionado - três textos criados e propagados pela empresa Todeschini, em períodos distintos - como um fato de linguagem por excelência que tem memória e, portanto, nos conduz à memória linguística (ORLANDI, 1995, p. 115), acreditamos que ele nos permitirá: i) acessar às FDs que o autoriza e, portanto, aos efeitos de sentidos; e ii) por meio das tomadas de posição, observar como sujeito ao dizer (com suas intenções e objetivos) não possui controle desse dizer, ou seja, os textos selecionados dizem de maneira completamente diferente em relação a eles próprios, o que nos faz pensar em (re)significação dos sentidos por tomadas de posição.

Diante disso, nosso trabalho aponta para a necessidade de intensificar a discussão teórica que evidencia os estudos sobre a heterogeneidade da linguagem. 


\section{Dois caminhos... Uma direção}

A partir de agora, discutiremos a noção de FD sob duas perspectivas: a primeira, em consonância com as contribuições foucaultianas - um caminho do qual desviaremos; e, a segunda, pautada nos postulados pêcheuxtianos - caminho no qual seguiremos.

\section{Um caminho do qual desviamos: a noção de Formação Discursiva em Michel Foucault}

Definir em sua individualidade singular um sistema de formação é, assim, caracterizar um discurso ou um grupo de enunciados pela regularidade de uma prática (FOUCAULT, 2005, p.82).

Embora já tenhamos evidenciado a pretensão de nos debruçarmos sobre a noção de FD em Michel Pêcheux, entendemos ser importante considerar a concepção de FD trazida por Foucault, tendo em vista a importância desses dois teóricos no arcabouço da Análise do Discurso de linha francesa, inclusive no que se refere à origem do próprio conceito de FD.

Baronas (2011) considera que há uma paternidade partilhada entre ambos, mas faz uma ressalva, pois muitos estudos, tanto na França quanto no Brasil, apontam que tal conceito surgiu, pela primeira vez, com Michel Foucault, em seu livro Arqueologia do Saber (1969), quando, na verdade, ele já havia sido enunciado no artigo Lexis et metalexis: les problemes des determinants, publicado em 1968, por Pêcheux e Fuchs, caindo por terra a noção de que Pêcheux teria emprestado a ideia de Foucault.

Contudo, não devemos perder o foco. Parafraseando Maldidier (1993), o que nos importa não é a origem da expressão, mas o seu deslocamento, a sua concepção como um "componente da Formação Ideológica", que determina "o que pode e deve ser dito a partir de uma dada posição numa dada conjuntura". E isso se deu com Pêcheux, a partir de 1977, quando ele reordena o conceito foucaultiano de FD que representava 
"uma primeira relação entre a História, vista sob os tipos de relações ideológicas de força nas sociedades de classe, e a materialidade linguageira" (MALDIDIER, 1993, p. 6).

Foucault deixou suas marcas no campo da Análise do Discurso, uma vez que trouxe, como de fundamental importância para esta área, a relação entre o sujeito, o discurso, a história e o poder. Segundo ele, para compreender a constituição da FD faz-se necessário considerar a importância dos elementos históricos, uma vez que o saber é uma construção histórica e, como tal, produz verdades que se instauram e se revelam nas práticas discursivas. O saber e o discurso são definidos baseados no conceito de enunciado e este "pertence a uma formação discursiva, como uma frase pertence a um texto, e uma proposição a um conjunto dedutivo" (FOUCAULT, 1969, p. 135).

É importante entender, conforme o filósofo, que enunciado não é sinônimo de proposição, de frase e tampouco de ato de fala, mas é ele que dá condições para que esses ocorram. O enunciado é regido por regras e faz parte dessa ou daquela FD, é ele que garante a existência de uma proposição que pode ou não ter sentido, de uma fala que vai ou não se encaixar naquele contexto, de uma frase que pode ser gramatical ou agramatical. Conforme Foucault (1969), um sistema linguístico só poderá ser estabelecido se utilizado um corpo de enunciados ou uma coleção de fatos de discurso. É necessário definir regras que permitam construir outros enunciados diferentes, possíveis - "um conjunto finito de regras que autoriza um número infinito de desempenhos" (FOUCAULT, 1969, p. 30).

O discurso, na concepção foucaultiana, é um conjunto de regras "anônimas e históricas" determinadas no tempo e no espaço, é um conjunto de enunciados que provêm da mesma formação discursiva. Por sua vez, a formação discursiva "caracteriza-se não por princípios de construção, mas por uma dispersão de fato, já que ela é para os enunciados não uma condição de possibilidades, mas uma lei de coexistência [...]" (FOUCAULT, 1969, p. 135).

Visando construir o conceito de FD, Foucault buscou, por meio de um projeto no campo da Análise de Discurso, encontrar algo que definisse o discurso numa única unidade. Assim, ele elegeu e analisou quatro categorias: formação dos objetos, relações dos modos enunciativos, formação dos conceitos e escolhas dos temas. Foram, a seu ver, quatro tentativas e quatro 
fracassos, mas ele quis prová-las e percebeu que não descreviam a realidade. Concluiu, então, que a dispersão era melhor que a unidade, encontrando, assim, o foco da sua análise. Em relação às quatro categorias analisadas, as regras de FD foram criadas seguindo as condições a que seus elementos estão submetidos.

Um ponto decisório que nos desviou do conceito de FD trazido por Foucault refere-se a sua consideração em termos de saber e de poder, não em termos de ideologia; o filósofo compreende FD numa perspectiva de dispersão, sendo estabelecidas as relações entre o dizer e o fazer e as práticas discursivas marcadas por uma não-autonomia. Em outras palavras, Foucault (1969) defendeu que, quando o sistema de dispersão fosse semelhante entre um determinado número de enunciados e quando uma regularidade pudesse ser definida entre as quatro categorias analisadas objetos, tipos de enunciação, conceitos e escolhas temáticas - haveria uma formação discursiva.

Enfim, conforme dito, a contribuição deste teórico é de fundamental importância para a Análise do Discurso e não haveria espaço suficiente, em um ensaio, para discorrer sobre ela. Contudo, tendo em vista o nosso objetivo, seguimos trazendo a concepção de FD na linha de Michel Pêcheux, pela qual seguirá nossa análise.

\section{Um caminho no qual seguimos: a noção de Formação Discursiva em Michel Pêcheux}

[...] a formação discursiva pode ser entendida como o que pode e deve ser dito pelo sujeito, ou seja, ela tem seus saberes regulados pela forma-sujeito e apresentase dotada de bastante unicidade [...] (INDURSKY, 2020, p. 306-307).

Michel Pêcheux, em parceria com Catherine Fuchs, atento às observações, interpretações, críticas e deformações no que se refere à difusão da análise automática do discurso (AAD), por meio do nível teórico e do nível das aplicações experimentais, propôs uma reformulação de conjunto, visando a eliminar certas ambiguidades, retificar certos erros, constatar certas dificuldades não-resolvidas e indicar as bases para uma 
nova formulação da questão (PÊCHEUX; FUCHS, 1990, p. 163). Nesse sentido, os autores trazem as noções de discurso e ideologia estabelecidas numa relação pela qual

[...] se deve conceber o discursivo como um dos aspectos materiais do que chamamos de materialidade ideológica. Dito de outro modo, a espécie discursiva pertence ao gênero ideológico, o que é o mesmo que dizer que as formações ideológicas comportam necessariamente, como um de seus componentes, uma ou várias formações discursivas interligadas que determinam o que pode e deve ser dito, a partir de uma posição dada numa conjuntura, isto é, numa relação de lugares no interior de um aparelho ideológico (PÊCHEUX; FUCHS, 1990, p.166167).

Percebe-se, portanto, que essa noção, desde sempre, é algo importante ao quadro teórico de Pêcheux por considerar as FDs atravessadas pela ideologia que faz parte, ou melhor, é a condição para a constituição dos sujeitos e dos sentidos. O indivíduo é interpelado em sujeito pela ideologia para que se produza o dizer (ORLANDI, 1995, p. 46). Também não esqueçamos da importância da convocação da noção de sujeito para formular a noção de FD.

Isso coloca em suspenso o modo homogêneo pelo qual se entende e se discute FD à margem dos postulados pêcheuxtianos: i) na perspectiva da não-falha, ou seja, da impossibilidade de conceber um sujeito que ao estar vinculado a uma dada FD, sujeitando-se, em concordância com os dizeres, identificando-se plenamente com o sujeito universal, à forma-sujeito, de fato um bom sujeito, poderia romper com essa FD ao ponto de inscrever-se em outra e comportar-se como tal; ii) entendida sem ideologia, da pureza, da neutralidade, de sujeitos livres que dizem e se dizem o que querem e como querem, senhores de si e, portanto, proprietários de consciência; iii) do discurso inscrito em uma única $\mathrm{FD}$, ou seja, da insistência da homogeneidade ilusória.

Diferentemente dessas percepções, entendemos que a interpelação do indivíduo em sujeito de seu discurso se efetua pela identificação com a formação discursiva que o domina (PÊCHEUX, 1988, p. 147). Vale salientar que embora essa "dominação", ou seja, o assujeitamento é uma noção compreendida fora da concepção pêcheuxtiana, na esteira da subserviência, 
da ingenuidade, da tolice, aqui a compreendemos enquanto movimento de interpelação dos indivíduos por uma ideologia, condição necessária para que o indivíduo se torne sujeito do seu discurso. E ainda, segundo Pêcheux, os indivíduos são interpelados em sujeitos de seu discurso, pelas formações discursivas que representam na linguagem as formações ideológicas que lhes são correspondentes (PÊCHEUX, 1988, p. 147).

Diante do exposto, uma questão precisa ser esclarecida: por que Michel Pêcheux apresenta-se como o melhor caminho para compreender FD? Convocamos Freda Indursky, que nos esclarecerá:

[...] é lícito afirmar que, no quadro teórico da Análise do Discurso, tal como formulado por Pêcheux, [...] ao contrário do que ocorre na Arqueologia de Foucault, não só é lícito falar em ideologia, como é ela, juntamente com o sujeito, que é tomada como princípio organizador da formação discursiva. Redizendo e já me posicionando: é o indivíduo que, interpelado pela ideologia, se constitui como sujeito, identificando-se com os dizeres da formação discursiva que representa, na linguagem, um recorte da formação ideológica (INDURSKY, 2020, p. 306).

A partir disso, passamos a observar, por meio das propagandas selecionadas da Todeschini, como a identificação do sujeito com os dizeres da FD muda. Assumimos como hipóteses que: i) no primeiro texto, o discurso racista convive harmoniosamente com os discursos de gênero e capitalista, todos autorizados por FDs que legitimam dizeres inaceitáveis à época atual; ii) na segunda propaganda, percebe-se, por um lado, o rompimento do sujeito com a FD que evidencia o discurso racista, embora podemos interpretar a permanência do racismo atuando por meio do não-dito e, por outro lado, o discurso de gênero e o discurso capitalista produzindo efeitos "parecidos" ao texto anterior; e iii) por fim, a terceira materialidade apresenta um rompimento com o discurso de gênero, mas não com o discurso capitalista. 


\section{Figura 1 A cozinha de antes}

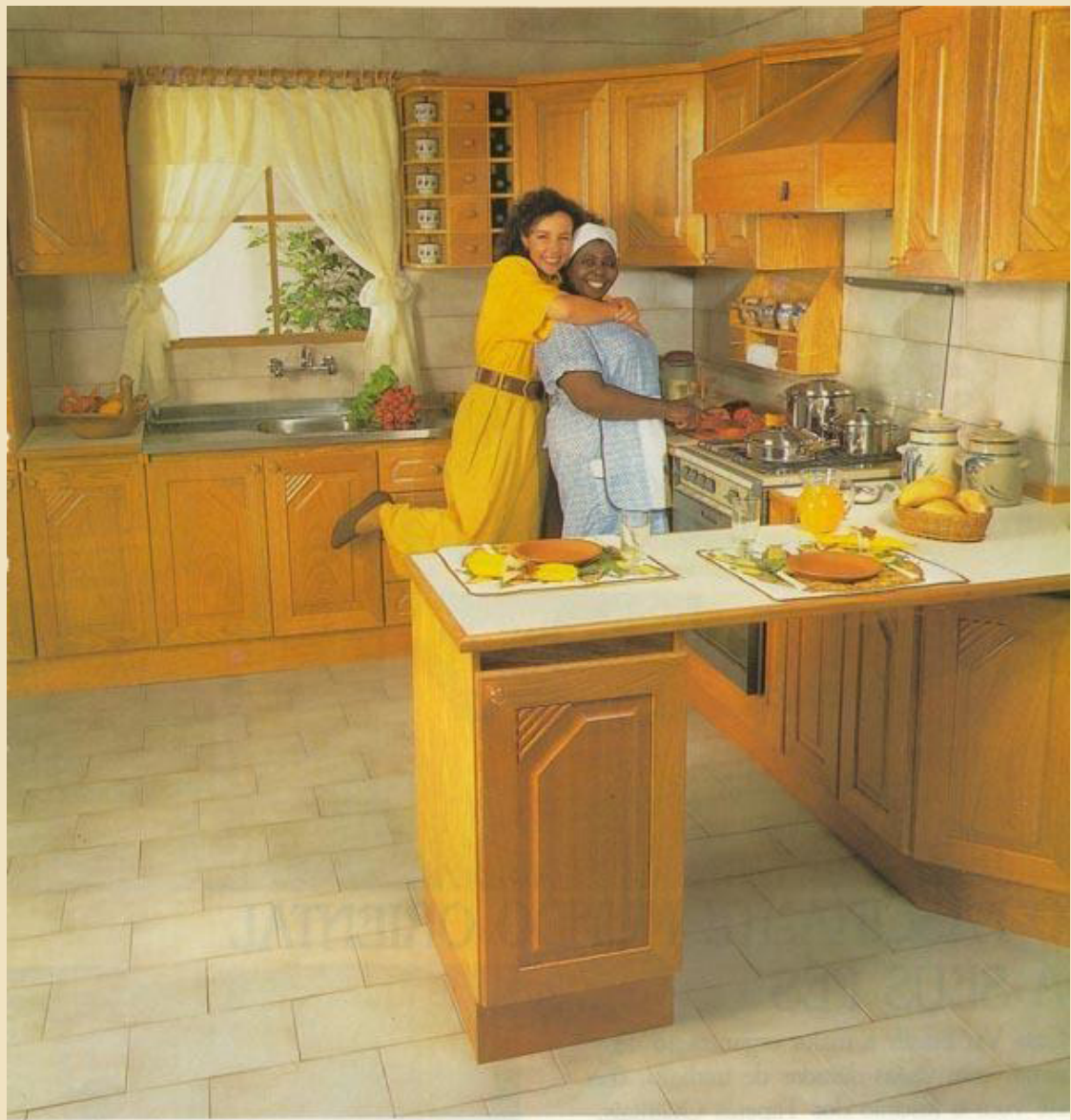

\section{Cozinhas Todeschini.}

A melhor maneira de segurar a sua empregada.

Se você é destas felizardas que possuem empregada e ainda não tem uma cozinha Todeschini, abra o olho. A sua vizinha pode estar comprando uma e andar de conversinhas no muro com a sua empregada. Afinal, quem não gosta de conforto? Uma cozinha Todeschini é o melhor lugar da casa.

Prática na sua funcionalidade e bom gosto em todos os detalhes. Podendo combinar e modular à vontade, dependendo do espaço e da sua necessidade.

Agora, se você ainda não tem uma empregada, faça este favor pra você mesma. Amanhã as coisas podem melhorar.

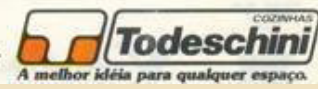

Fonte: <https://www.propagandashistoricas.com.br/2020/07/cozinha-todeschini.

html>. Acesso em: 20 set. 2020

Embora sejamos péssimos sujeitos devido a nossa desidentificação com as FDs vigentes no texto acima, precisamos entendê-las. Se considerarmos o contexto sócio-histórico, isto é, a exterioridade, 
entendemos que essas premissas foram preponderantes para a legitimação de tais dizeres. Os enunciados, em especial, "a melhor maneira de segurar sua empregada" e "Se você é destas felizardas que possuem empregada..." (grifos nossos), somados à fotografia de uma mulher de pele branca, provavelmente a patroa, "abraçando" numa teatralização que sugere uma "prisão" de uma mulher de pele negra, a empregada, endossam FDs que entendem e reforçam o lugar das mulheres: i) ambas na cozinha, espaço designado para elas, uma vez que "lugar de mulher é na cozinha"; ii) a demarcação do território da cozinha: o espaço da patroa difere do espaço da empregada. Ademais, a figura da mulher de pele negra, usando uniforme, reporta-nos à memória discursiva na qual essa mulher representa as escravizadas do período colonial, época na qual era legítimo segurar e possuir seres humanos. Por fim, o discurso capitalista é reforçado pela ideia da compra da cozinha Todeschini, afinal, é necessário "abrir o olho" com a concorrência para que sua empregada "não fique, em cima do muro, de conversinhas com a vizinha".

Assim, ao elegermos esta propaganda, percebemos que há uma identificação do sujeito com as FDs que o interpelam, o que, de acordo com Pêcheux, chamamos de primeira modalidade. Indursky (2020), diz que

a primeira modalidade remete ao que Pêcheux designou de superposição entre o sujeito do discurso e a forma-sujeito. Tal superposição revela uma identificação plena do sujeito do discurso com a forma-sujeito da FD que afeta o sujeito [...]”. E que nada mais é do que foi descrito por ele como a reduplicação da identificação, tal como vimos nos parágrafos precedentes e que representam a primeira formulação destas noções, no âmbito do quadro teórico da AD (INDURSKY, 2020, p. 308).

Em outras palavras: o sujeito do discurso é um bom sujeito. 


\section{Figura 2 A cozinha e algumas mudanças}

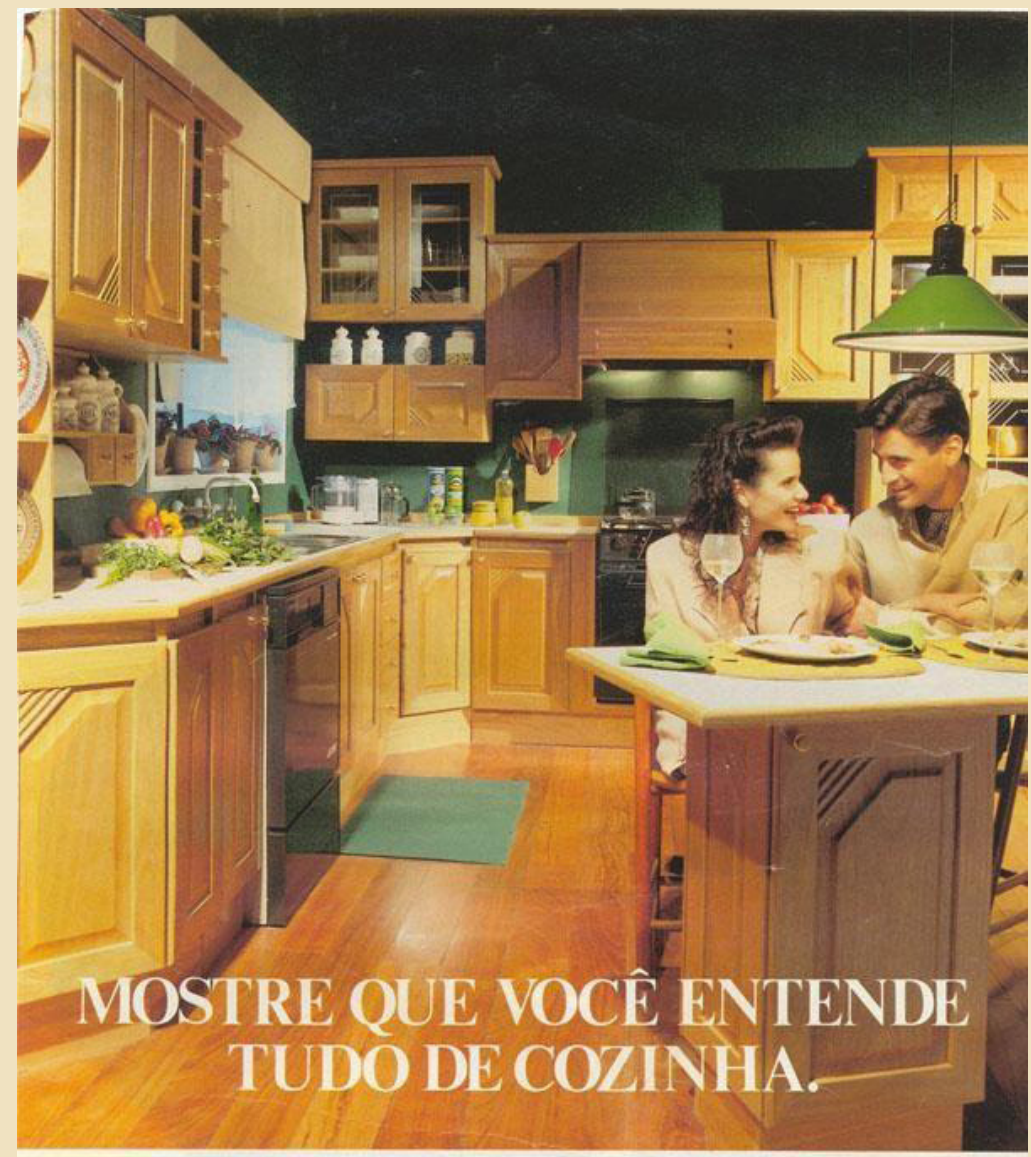

Entender de cozinha năo significa saber preparar molhos ou temperos especiais. Mesmo quem nāo sabe nem fritar um ovo, sabe que Todeschini é a melhor cozinha que existe. Qualidade em todos os detalhes e uma racionalizaçāo de espaço impressionante. Se você quer agradar na cozinha, comece com Todeschini.

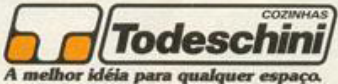

Fonte: <http://www.propagandaemrevista.com.br/propaganda/97/>. Acesso em: 20 set. 2020 
Mesmo tendo ocorrido algumas mudanças, ainda nos consideramos péssimos sujeitos, pois prevalece nossa desidentificação com as FDs vigentes no texto acima.

Nessa propaganda, o discurso capitalista segue evidenciado pelas semioses, trata-se de um texto de finalidade comercial pelo qual reforça-se que "Todeschini é a melhor cozinha que existe". Por outro lado, o discurso de gênero, autorizado por FDs, segue produzindo efeitos "parecidos" ao texto anterior: a mulher continua "no seu lugar" e, agora, servindo a um homem. O enunciado "Entender de cozinha não significa saber preparar molhos ou temperos especiais" endossa uma competência que toda mulher "deve ter": a capacidade de servir. O lugar da mulher, enquanto aquela que serve, e o lugar do homem, aquele que é servido, apontam para o discurso de gênero que sempre coloca a figura feminina num espaço desprestigiado em relação ao ser masculino.

O discurso racista, conforme discutimos no primeiro texto, não se evidencia nesse segundo. Tal constatação nos faz perceber que houve aí um processo pelo qual o sujeito do discurso não se comportou como um bom sujeito. Em outras palavras: os dizerem que reforçam o discurso racista não mais são aceitos, uma vez que houve um possível rompimento do sujeito com a FD. O sujeito, por uma tomada de posição, se contrapõe ao sujeito universal, o que configura o mau sujeito. Essa modalidade

[...] caracteriza o discurso do "mau sujeito", discurso em que o sujeito do discurso, através de uma "tomada de posição", se contrapõe à forma-sujeito e aos saberes que ela organiza no interior da Formação Discursiva. Essa segunda modalidade consiste em "uma separação (distanciamento, dúvida, questionamento, contestação, revolta...)" em relação ao que diz a forma-sujeito, conduzindo o sujeito do discurso a contra-identificar-se com alguns saberes da formação discursiva que o afeta (INDURSKY, 2020, p. 308). 
Figura 3 A cozinha de hoje

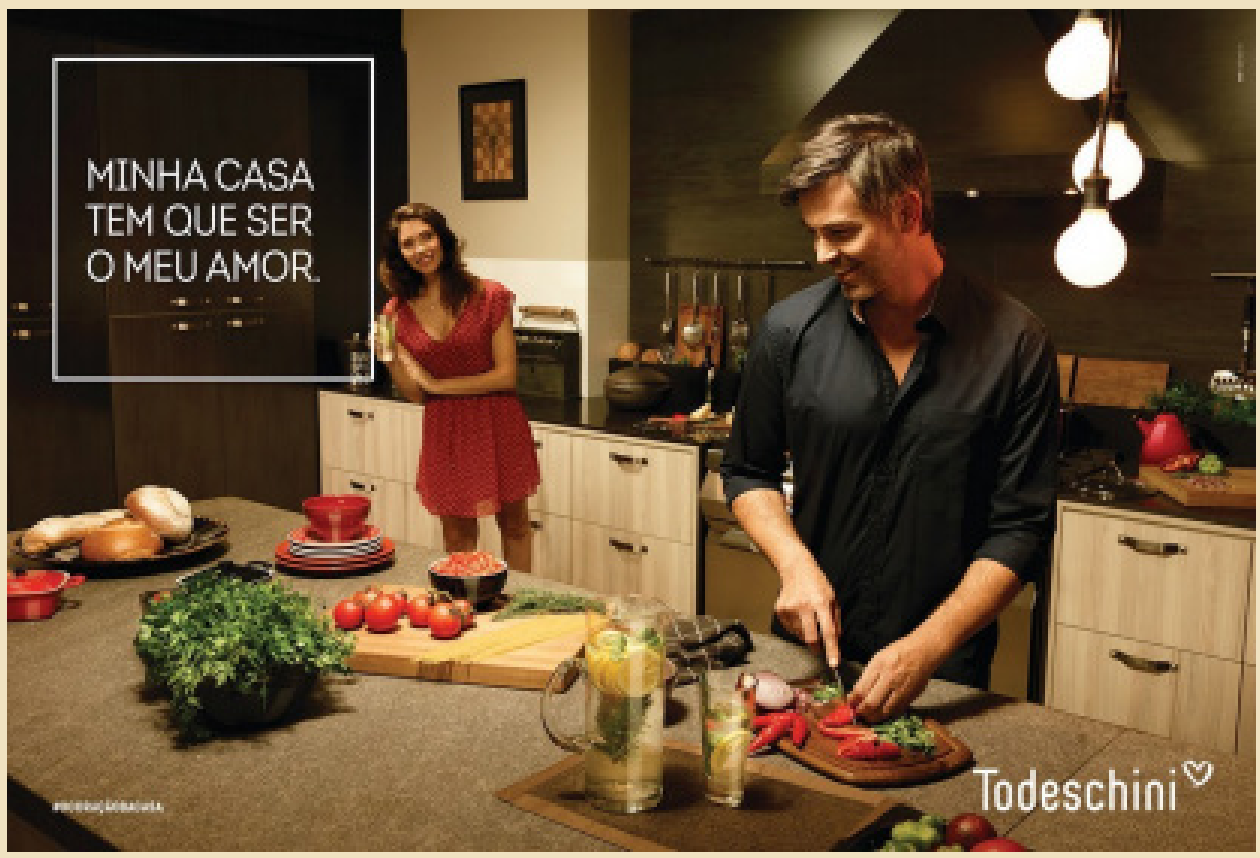

Fonte: <https://www.behance.net/gallery/29854801/Todeschini-Colecao\%20 Ser2016>. Acesso em: 20 set. 2020

Em relação a esse terceiro texto, que traduz bem a situação sóciohistórica atual, somos quase bons sujeitos, uma vez que nos identificamos, em parte, com o discurso presente. Assim como nos anteriores, o discurso capitalista apresenta-se em sua forma plena: i) pelo enunciado "Minha casa tem que ser o meu amor", no qual "amor" acomoda uma ambiguidade - a pessoa e a cozinha Todeschini; ii) pela representação da fartura de alimentos sobre a bancada e objetos tidos como elegantes (luminárias, tábuas, acessórios), pelo comportamento consumista reiterado pelo capitalismo.

No que se refere ao discurso de gênero, percebe-se uma ruptura com a ideia preconceituosa de que "lugar da mulher é na cozinha". O homem apresentado na propaganda ocupa "o lugar feminino"; a mulher, por sua vez, espera para ser servida. Essa encenação denuncia uma desidentificação do sujeito do discurso com o discurso machista. Assim, o rompimento do sujeito com a FD aconteceu por meio de uma tomada de posição não subjetiva. Dito de outra forma: 
O modo da "desidentificação, isto é, de uma tomada de posição não-subjetiva, que conduz ao trabalho de transformação deslocamento da forma-sujeito", ou seja, o sujeito do discurso desidentifica-se de uma formação discursiva e sua forma-sujeito para deslocar sua identificação para outra formação discursiva e sua respectiva forma-sujeito (INDURSKY, 2020, p. 310).

Portanto, faz-se necessário perceber o sujeito do discurso identificando-se, contra-identificando-se ou desidentificando-se com FDs para que percebamos como somos interpelados pelas formações ideológicas. Daí a necessidade de tal estudo, embora que por um ato de consciência, devemos compreender como somos assujeitados nas e pelas FDs nas quais nos inscrevemos. Mais uma vez, convocamos Indursky. Ela nos mostra a relevância de lutar pela FD:

Julgo, pois, que a FD merece que lutemos por ela, desde que se entenda que não é possível cristalizá-la; desde que ela não se converta em um colete rígido que impeça a fragmentação da forma-sujeito; desde que se entenda que não há ritual sem falhas e que esta falha permite que novos saberes podem inscrever-se, obedecendo ao princípio da transformação; desde que saibamos que esta falha no ritual conduz o sujeito do discurso a apropriar-se de saberes alheios e inserilos no âmbito de uma FD. Ou seja: a FD deve ser tomada como uma unidade dividida em relação a si mesma, a qual comporta em seu interior diferentes posições-sujeito que representam a fragmentação da forma-sujeito. Penso que é difícil suportar a diferença, mas é ela que mostra que a FD, e não apenas o discurso, é lugar de tensão e não apenas de segurança (INDURSKY, 2020, p. 316).

\section{Uma ilusão necessária}

Embora a FD pareça homogênea, sem possibilidade de interferência, dotada de unicidade, ela não o é, haja vista suas porosidades que podem levar o sujeito do discurso a significá-la diferentemente, considerando a ideologia vigente. 
No primeiro texto analisado, percebemos que o "bom sujeito" identifica-se com as FDs apresentadas, sendo possível os discursos sobre a exclusividade das mulheres ocuparem a cozinha, "segurar a empregada" (negra) e a compra de um produto Todeschini ser sinônimo de conforto e praticidade. No entanto, já no segundo texto, observamos uma desidentificação do sujeito com a FD do discurso racista. Não é mais permitido "segurar a empregada" ou achar que "ela pode ser tomada pela vizinha". Por outro lado, o discurso de gênero foi ressignificado ao ponto de que o espaço da cozinha passou a ser habitado por um homem, mesmo que na condição de quem é servido. Já no terceiro texto, o sujeito desidentificase com a FD que legitima o discurso da mulher subserviente às necessidades masculinas, ou seja, o homem passa a servir à mulher. O discurso capitalista, em todos os textos, foi endossado pelas FDs que interpelam o sujeito. Portanto, nossas hipóteses foram confirmadas pelas análises realizadas que nos mostram: os sentidos mudam e a cozinha também.

Nesses processos, nos quais trouxemos o sujeito do discurso como foco, nossa pretensão foi mostrar que a interpelação da ideologia, por meio das tomadas de posição, dá-se por aquilo que Pêcheux chamou de falha no ritual. Embora não tenhamos espaço para problematizar esse conceito, faremos a última convocação de Indursky que nos esclarecerá:

É precisamente sobre o que estou chamando de falhas no ritual que penso ser necessário colocar o foco: no meu entendimento, a falha no ritual remete para uma falha na interpelação do sujeito, ou seja: é porque o ritual é sujeito a falhas que o sujeito pode se contraidentificar com os saberes de sua formação discursiva e passar a questioná-los, fragmentando a forma-sujeito e produzindo diferentes posições-sujeito (INDURSKY, 2020, p. 314).

\section{Referências}

BARONAS, R. L., Formação discursiva em Pêcheux e Foucault: uma estranha paternidade. In: Sargentini, V., NAVARRO-BARBOSA, P. (orgs.). M. Foucault e os domínios da linguagem: discurso, poder, subjetividade. São Carlos: Claraluz, 2004, p. 45-62. 
FOUCAULT, M. Arqueologia do saber. 6. ed. Rio de Janeiro: Forense Universitária, 1969.

INDURSKY, Freda. A fragmentação do sujeito em análise do discurso. In: INDURSKY, F. Discurso, memória, identidade. Porto Alegre: Sagra Luzzatto, 2000. (Col. Ensaios, 15).

INDURSKY, Freda. A noção de sujeito em Análise do Discurso: do desdobramento à fragmentação. ANPOLL, CD-ROM Síntese 2, Porto Alegre, 2002.

INDURSKY, Freda. Da interpelação à falha no ritual: a trajetória teórica da noção de formação discursiva. In: BARONAS, R. L. (org.). Análise de discurso: apontamentos para uma história da noção-conceito de formação discursiva. Araraquara: Letraria, 2020.

INDURSKY, Freda. Formação discursiva: esta noção ainda merece que lutemos por ela? In: BARONAS, R. L.; LEANDRO FERREIRA, M. C. (org.). Análise do Discurso no Brasil: mapeando conceitos, confrontando limites. São Carlos/SP: Claraluz, 2007b, p. 163-72.

MALDIDIER, D. A inquietude do discurso. Um trajeto na história da análise do discurso: o trabalho de Michel Pêcheux. Semen, número 8, 1993, p. 107-119. Disponível em: <https://www.passeidireto.com/arquivo/4568978/ maldidier-denise-a-inquietude-do-discurso-um-trajeto-na-historia-daanalise-do-d)>. Acesso em 20/07/2020.

PÊCHEUX, M.; FUCHS, C. A propósito da análise automática do discurso: atualização e perspectivas. In: GADET, F.; HAK, T. (org.). Por uma análise automática do discurso. Campinas: Ed. da UNICAMP, 1990.

PÊCHEUX, M. Semântica e Discurso: uma crítica à afirmação do óbvio. Campinas: Ed. da UNICAMP, 1988.

ORLANDI, Eni P. Texto e discurso. Organon. Porto Alegre, Revista do Instituto Letras/UFRGS, v. 9, n. 23, p. 63-68, 1995. 